\title{
How much CABG is good for us?
}

\section{Citation}

Jones, David S. 2012. "How Much CABG Is Good for Us?" Lancet 380 (9841) (August): 557-558.

doi:10.1016/s0140-6736(12)61319-1. http://dx.doi.org/10.1016/S0140-6736(12)61319-1.

\section{Published Version}

doi:10.1016/s0140-6736(12)61319-1

\section{Permanent link}

http://nrs.harvard.edu/urn-3:HUL.InstRepos:11880308

\section{Terms of Use}

This article was downloaded from Harvard University's DASH repository, and is made available under the terms and conditions applicable to Open Access Policy Articles, as set forth at http:// nrs.harvard.edu/urn-3:HUL.InstRepos:dash.current.terms-of-use\#OAP

\section{Share Your Story}

The Harvard community has made this article openly available.

Please share how this access benefits you. Submit a story.

Accessibility 


\section{How Much CABG Is Good For Us?}

In 1977 the Society of Thoracic and Cardiovascular Surgeons of Great Britain and Northern Ireland established its Cardiac Surgical Registry with the hope that it would "promote the rational use and future planning" of cardiac surgery. The Registry revealed important developments. The use of coronary artery bypass grafting (CABG) doubled by 1982. Marked geographic variation in CABG utilization also emerged, with rates in London 10-times higher that those in Oxford or the South Western regions. The disparities could be explained, in part, as a historical artifact: cardiac surgery centers were first established in medical schools, and these were concentrated in London. Cardiac surgeons were more concerned about the overall rate. Even though the UK CABG rate had risen sharply, it compared "unfavourably" with the rate in Australia (which was 4-times higher) and the United States (7-times higher). Why "unfavourably"? Which country, if any, had the right rate? This question has vexed physicians for decades. As coronary heart disease (CHD) tightens its grip as the world's leading cause of death, the answer is of growing importance to global health policy.

Even though scholars have mapped epidemics for centuries, they only recently began making maps surgery and other therapies. J. Alison Glover might have made the first. On a Friday evening in May 1938 he presented a curious talk to the Royal Society of Medicine. He was concerned not just by the dramatic rise of tonsillectomy in England, but also by the marked variations between 
London neighborhoods. A child in Enfield was 20-times more likely to have had the procedure than one in Hornsey. Such "strange facts" defied easy explanation.

Widespread concern, however, did not take root for thirty years. In 1968 researchers compared surgery rates in Liverpool, Uppsala, and New England and found peculiar patterns of variation. While Americans led the pack with tonsillectomy, prostate surgery, and hernia repair, Swedes removed the most appendices and gallbladders. John Wennberg, meanwhile, studied practice variation in Vermont and found 3- to 10-fold variation in surgery rates. Neighboring regions often had disparate rates. These reports and many others in the early 1970 s revealed variation in surgery rates that did not simply reflect variations in the underlying burden of disease.

It was at this moment that CABG began its rise to prominence. Although surgeons in New York, Baltimore, Houston, Ann Arbor, and Leningrad had dabbled with the procedure in the 1960s, Cleveland Clinic surgeons earned the procedure wide acclaim in 1968. Leading medical centers followed suit. A map of CABG in the early 1970 s would have shown a patchy distribution, with a few hospitals doing hundreds of cases each year, while most did few or none at all. CABG, however, soon colonized the medical marketplace. By 1975 nearly 400 hospitals in the United States offered bypass surgery. The procedure had also spread to England, Europe, Argentina, Australia, and beyond.

The rise of $C A B G$ triggered fierce controversy. As surgeons ramped up their case loads, skeptics argued that the procedure performed no better than 
medical therapy in most patients. These tensions sharpened the interest in practice variation. The UK Registry exposed marked disparities within England. Similar variation was found within Australia and the United States. As the problem of "unwarranted variation" captured more and more attention, researchers collected data in ever increasing detail and analyzed them with ever more powerful computers. Wennberg linked up with a small group of economists and health researchers to produce the Dartmouth Atlas of Health Care. The Atlas mined US Medicare data to reveal variations in per capita spending, physician density, and procedure rates. A 1999 report commissioned by the American College of Cardiology and the Society of Thoracic Surgeons found the now-familiar variations in cardiac care. The prevalence of cardiac surgeons varied 5-fold and cardiologists 6-fold. Procedures varied as well, with 5-fold and 8-fold differences for CABG and angioplasty.

Recognition of pervasive practice variation caused a stir. In 1983 the US Institute of Medicine convened a conference on geographic disparities. The Institute's president, Frederick Robbins, worried about "'the potentially damning evidence that these great variations represent"': "it looks bad, and it looks bad because it is bad. It is not an appropriate way for a profession to behave."' Clinicians remained convinced that the variations in CABG and other therapies did not simply reflect variations in the underlying burden of disease. Instead, variation reflected a sordid mix of other factors. When the 1968 international comparisons found lower rates of surgery in Liverpool than in Uppsala or New England, the researchers wondered whether the "absence of financial incentives 
to the surgeons to operate may be a factor in restraining the scalpel." Did the presence of twelve ear nose and throat surgeons in Liverpool, compared with just one urologist, account for that city's high rate of tonsillectomy and low rate of prostatectomy? The team noted wryly "that whereas the tonsils have their predator, the prostate is left to flourish unattended."

Subsequent studies looked beyond financial conflicts of interest and supplier-induced demand to consider everything from the influence of local training programs to variations in national character. Even the RAND Corporation, the Cold War think tank famous for formulating the strategy of mutually assured destruction, entered the fray. In 1985 it assembled two panels of English doctors and one panel of American doctors and presented each with clinical vignettes of CABG patients. English doctors rated $35 \%$ of the cases "inappropriate," while the Americans flagged only $13 \%$. Since the panels were asked to ignore cost, the researchers concluded that "differences between them probably relate to their interpretation of scientific publications and to cultural factors that are difficult to identify." In some cases the judgment has been starker. One Louisiana cardiologist was indicted in 2006 on charges that he falsified clinical findings to justify unnecessary angioplasty and stenting. Convicted in 2009 , he was sentenced to ten years in prison.

As debate continues about the causes of unwarranted variation, physicians and health systems researchers continue to refine their data. The UK's Registry morphed into the National Adult Cardiac Surgical Database, which released its 6th annual report in 2008. A 2005 report from the Chief Medical 
Officer of the Department of Health examined NHS data and found that allocation of revascularization was "not currently equitable." A King's Fund investigation confirmed this in 2011: CABG rates ranged from 34/100,000 in the Westminster PCT to $197 / 100,000$ in Berkshire PCT. Was one of these rates right? The targets set by the Department of Health and the NHS keep shifting, from $30 / 100,000$ in 1984 to $150 / 100,000$ in 2000 .

International comparisons are equally troubling. In 1984 British surgeons thought that their $C A B G$ rate was unfavourably low, but many people now consider the US revascularization rates to be too high: patients in the United States do no better after heart attacks than their less frequently revascularized Canadian peers. OECD data from 2009 show a 7 -fold variation in angioplasty rates between Germany and Ireland, with the United States and England distributed in between. These disparities are dwarfed by those beyond Europe. Barely visible at the bottom of the OECD chart sat Mexico, with an angioplasty rate scarcely $1 / 300$ th of that in Germany despite a similar CHD mortality rate. Revascularization is even less accessible in China and India.

It might once have been acceptable to dismiss these disparities as appropriate. CHD, after all, was long seen as a disease of the industrialized west. But health officials have known for the past two decades that this is not the case. In its 1993 World Development Report, the World Bank reported that CHD had already become the leading cause of death worldwide. India now has more heart attack deaths than any other country. Turkmenistan and Ukraine have the highest $\mathrm{CHD}$ mortality rates. Investments in cardiac care have not followed the 
rising tide of deaths. It may be true that coronary revascularization is over-used in Germany and the United States, but even the "low" rate in England towers above that in Mexico. The World Bank and the Institute of Medicine have encouraged aspirin, beta blockers, and other low cost medications while advising poor countries to avoid "sophisticated, expensive technologies" such as angiography, angioplasty, and CABG. Recent advocacy has finally pushed noncommunicable disease onto the global health agenda. Initial efforts culminated last fall when world leaders met in New York City for the General Assembly on the Prevention and Control of Non-communicable Diseases. But even there the attention remained focused on tobacco, diet, and lifestyle: "Prevention must be the cornerstone of the global response to noncommunicable diseases."

Should our response to the global spread of CHD be limited to prevention? The conventional wisdom holds that low- and middle-income countries should not invest in CABG and angioplasty: the techniques are said to be too difficult and too expensive to deploy in resource-poor settings. But that exact same critique was once leveled against antiretroviral therapy for AIDS -- it was too difficult to ensure adherence with the complex regimens, and the drugs were too expensive. It took many years of concerted effort by AIDS activists to shift the consensus from prevention to treatment, an effort that culminated in the Global Fund for the Prevention of AIDS, Tuberculosis and Malaria and the President's Emergency Program for AIDS Relief.

No one has yet identified the lack of access to coronary revascularization as a human rights crisis. There is no Global Fund or President's Emergency 
Program for Heart Attacks. Should there be? The inability of physicians in England, Europe, and the United States to establish and achieve target rates for CABG and angioplasty foretells a stormy course before progress is made towards global health equity in cardiac care. The revascularization rate in the United States is likely too high and the rate in Mexico is surely too low. What rate is the right rate? England might actually represent a happy mean, but physicians have not yet learned how to provide a convincing answer. Nor have they developed a plan to help the millions of heart attack patients each year in low- and middle-income countries whose lives could be saved with prompt use of these interventions.

David S. Jones Harvard University 


\section{Recommendations for Further Reading:}

David S. Jones, Fixing Hearts, Harming Brains: The Tangled History of Cardiac Care (Baltimore, MD: Johns Hopkins University Press, 2013).

English, T.A.H., A.R. Bailey, J.F. Dark, and W.G. Williams. "The UK Cardiac Surgical Register, 1977-82." British Medical Journal 289 (3 November 1984): 1205-1208.

Glover, J. Alison. "The Incidence of Tonsillectomy in School Children."

Proceedings of the Royal Society of Medicine 31 (1938): 1219-1236.

Pearson R. John C., Björn Smedby, Ragnar Berfenstam, Robert F.L. Logan, Alex Burgess, and Osler L. Peterson. "Hospital caseloads in Liverpool, New England and Uppsala. An international comparison." Lancet 292 (7 September 1968): 559-566.

John E. Wennberg, Tracking Medicine: A Researcher's Quest to Understand Health Care (New York: Oxford University Press, 2010). Dartmouth Atlas of Cardiovascular Care. Center for the Evaluative Clinical Sciences, Dartmouth Medical School, and the Center for Outcomes Research and Evaluation, Maine Medical Center. Chicago: AHA Press, 1999.

Iglehart, John K. "From the Editor." Health Affairs 3 (Summer 1984).

Brook, Robert H., Jacqueline B. Kosecoff, R.E. Park, Mark R. Chassin, Constance M. Winslow, and J.R. Hampton. "Diagnosis and Treatment of 
Coronary Disease: Comparison of Doctors' Attitudes in the USA and the UK." Lancet 331 (2 April 1988): 750-753.

Department of Health. The Chief Medical Officer on the state of public health Annual Report 2005. London: DH Publications, 2006.

King's Fund. "Widespread variations in rates of surgery are unfair and inefficient, new study finds." Press Release 14 April 2011. Available at http://www.kingsfund.org.uk/press/press releases/healthcare variation.ht $\underline{\mathrm{ml}}$

OECD, Health at a Glance 2011: OECD Indicators (OECD Publishing, 2011). Available at http://dx/doi/org/10.1787/health glance-2011-en.

World Bank. Investing in Health: World Development Report 1993. New York: Oxford University Press, 1993.

Howso, Christopher P., K. Srinath Reddy, Thomas J. Ryan, and Judith R. Bale, ed., for the Institute of Medicine. Control of Cardiovascular Diseases in Developing Countries: Research, Development, and Institutional Strengthening. Washington, DC: National Academies Press, 1998.

General Assembly of the United Nations. "Political Declaration of the High-level Meeting of the General Assembly on the Prevention and Control of Noncommunicable Diseases.” Draft Resolution, 16 September 2011. Accessed 30 October 2011. http://www.un.org/en/ga/ncdmeeting2011/ 